\title{
Two-position measurement of intraocular pressure by PTI 00 noncontact tonometry in comparison with Goldmann tonometry
}

This article was published in the following Dove Press journal:

Clinical Ophthalmology

27 August 2011

Number of times this article has been viewed

\author{
Kelechi C Ogbuehi \\ John C Chijuka \\ Uchechukwu L Osuagwu
}

Correspondence: Uchechukwu L Osuagwu Cornea Research Chair,

Department of Optometry, College

of Applied Medical Sciences, King Saud

University, PO Box 10219, Riyadh II433,

Kingdom of Saudi Arabia

Tel +966 I4693530

Fax +966I4693556

Email uosuagwu@ksu.edu.sa
Background: The purpose of this study was to evaluate the precision of intraocular pressure measurements obtained by PT100 noncontact tonometry in a handheld and slit lamp-mounted position in comparison with that of Goldmann applanation tonometry in healthy young adults.

Methods: Sixty eyes from 60 subjects (30 men and 30 women) aged $22 \pm 1$ (range 20-24) years participated in this study. Triplicate intraocular pressure measurement of a randomly selected eye was obtained by a noncontact tonometer in a handheld and slit lamp-mounted position in a randomized order, with the Goldmann applanation tonometer always performed last. A second measurement session was carried out after one week to assess repeatability.

Results: The mean \pm standard deviation of intraocular pressure readings in the first and second session, respectively, with the three techniques were: handheld position, $14.52 \pm 3.28 \mathrm{mmHg}$ and $15.26 \pm 2.11 \mathrm{mmHg}$; slit lamp-mounted position, $14.01 \pm 2.80 \mathrm{mmHg}$ and $15.16 \pm 2.34 \mathrm{mmHg}$; and Goldmann applanation tonometer, $14.86 \pm 3.26 \mathrm{mmHg}$ and $15.16 \pm 2.42 \mathrm{mmHg}$. There were no significant differences $(P>0.05)$ between the techniques in the intraocular pressure measurements returned (Goldmann applanation tonometer vs handheld and Goldmann applanation tonometer vs slit lamp-mounted). The Goldmann applanation tonometer measured intraocular pressure $0.34 \mathrm{mmHg}$ higher than handheld and $0.85 \mathrm{mmHg}$ higher than slit lamp-mounted in session 1, and in session 2 Goldmann applanation tonometer intraocular pressure measurement was the same as with the slit lamp-mounted method but lower than with the handheld method by $0.11 \mathrm{mmHg}$. In PT100 handheld vs slit lamp-mounted comparisons, there were no significant differences $(P>0.05)$ between intraocular pressure measurements returned by both techniques in sessions 1 and 2. Intrasession and intersession repeatability coefficients for Goldmann applanation tonometer intraocular pressure and slit lamp-mounted intraocular pressure were similar, and better in comparison with those for handheld intraocular pressure.

Conclusion: The Goldmann applanation tonometer and PT100 noncontact tonometer in both positions studied here are reliable, consistent techniques for measurement of intraocular pressure, and can be used interchangeably for obtaining intraocular pressure values in young normal subjects. Repositioning of the PT100 tonometer from hand-held to slit lamp-mounted improved its precision and reduced variation with respect to the Goldmann applanation tonometer.

Keywords: intraocular pressure, Goldmann applanation tonometry, Reichert PT100 noncontact tonometer, handheld, slit lamp-mounted, repeatability

\section{Introduction}

Intraocular pressure is currently the only treatable risk factor for developing primary open-angle glaucoma, and when neglected, predisposes the eye to subsequent deterioration in vision and visual field damage. ${ }^{1}$ It is one of a ternary of clinical signs monitored 
for the diagnosis and/or management of glaucoma, especially primary open-angle glaucoma, in which the pathogenesis of the disease is insidious. ${ }^{2}$ Intraocular pressure measurement is essential in glaucoma diagnosis and also in assessment of the efficiency of glaucoma treatment with various antiglaucoma agents. ${ }^{3}$

The Goldmann applanation tonometer is the gold standard in clinical practice for measurement of intraocular pressure, against which all other types of tonometers are compared. Although manometry is the most accurate method, its invasive nature has limited its applications in clinical settings. ${ }^{4}$ While the Goldmann applanation tonometer is preferred in adults, it is often inconvenient or impossible to use in children, which is why devices such as PT100 were developed. ${ }^{5,6}$ Goldmann tonometry requires the instillation of fluorescein, ocular topical anesthesia, and corneal contact to obtain precise intraocular pressure measurements. To do this, the probe must be in contact with the central cornea so as to applanate a fixed corneal area, thereby increasing the risk of spreading infectious diseases of the cornea and conjunctiva, and of possible damage to the corneal epithelium. ${ }^{7}$ The Goldmann applanation tonometer only gives an estimate of the true intraocular pressure as measured by manometry. However, the accuracy of noncontact tonometers is limited by the accuracy of the Goldmann applanation tonometer, because they are all calibrated against it. ${ }^{8}$ Description of the clinical use of noncontact tonometers introduced in 1974 by Forbes et $\mathrm{al}^{9}$ has since undergone various transitions and has led to technological improvements in the design and manufacture of more accurate, reliable, and easy to use noncontact tonometers.

Several studies have compared intraocular pressure measurements made with noncontact tonometers and Goldmann tonometers. ${ }^{2,10-13}$ In one study, ${ }^{13}$ the accuracy of two noncontact tonometers, including the Reichert AT550, Goldmann applanation tonometer, and a Perkins tonometer was tested in a young normal population. The results showed a high level of agreement between the AT550 and Goldmann applanation tonometer. Therefore, the investigators concluded that intraocular pressure readings obtained by AT550 are comparable clinically with those obtained by the Goldmann applanation tonometer in a population having intraocular pressure within the normal range. ${ }^{13}$ However, very few studies have compared readings obtained by the PT100 and Goldmann applanation tonometer. So far, three studies have reported a good correlation between the PT100 and Goldmann applanation tonometer. ${ }^{11,14,15}$ Murase et al ${ }^{14}$ analyzed their data based on the effect of central corneal thickness on intraocular pressure measurements obtained by the PT100 and the Goldmann applanation tonometer, whilst the comparative study of the PT100 and the Goldmann applanation tonometer done by Salim et $\mathrm{al}^{11}$ had a large variation in age among the recruited subjects, which may have affected the accuracy of their results. However, neither the Salim et al ${ }^{11}$ nor Murase et al study ${ }^{14}$ was able to demonstrate the repeatability of intraocular pressure measurements in normotensive subjects obtained by the PT100 NCT when compared with the Goldmann applanation tonometer. The only study to demonstrate the repeatability of Goldmann applanation tonometry in comparison with the PT100 observed that the intrasession repeatability of both techniques for test-retest differences was within $\pm 5 \mathrm{mmHg} .{ }^{15}$ It is important to note that the intraocular pressure measurements in the three studies cited above were obtained by the PT100 noncontact tonometer in a handheld position.

The portable noncontact tonometer, Reichert PT100 (Buffalo, Depew, NY) is increasingly used in optometry practices due to its rapidity and convenience in obtaining intraocular pressure measurements. It is also the first truly handheld noncontact tonometer (this increases its versatility), making it a useful screening instrument in preference to the Goldmann applanation tonometer. The readings obtained by noncontact tonometers are largely independent of the operator. ${ }^{16}$ While one study ${ }^{15}$ noted no statistically significant difference in mean intraocular pressures measured by Goldmann applanation tonometer and the PT100, another study ${ }^{11}$ observed a significant difference in intraocular pressure measurements returned by the Goldmann applanation tonometer and the PT100 when handheld. They further suggested that instability of the PT100 instrument was a possible reason for the variation in intraocular pressure readings between the Goldmann applanation tonometer and the PT100. Hence, this study was conducted to assess any possible differences in the precision of intraocular pressure measurements obtained when the PT100 noncontact tonometer was used in different positions (handheld and slit lamp-mounted) in comparison with the Goldmann applanation tonometer intraocular pressure measurements.

\section{Methods \\ Data}

Data for this study were obtained from 69 subjects recruited from students of various colleges at King Saud University. The study adhered to the tenets of the Declaration of Helsinki, and the protocol was approved by the ethics committee of the College of Applied Medical Sciences, King Saud 
University. Each subject gave their informed consent, after having the risks and benefits of participation explained to them. For inclusion in this study, subjects were required to be oculovisually healthy during the study period, and should not have participated in any of our similar studies. Patients with any corneal disease, previous history of corneal surgery, glaucoma or a family history of glaucoma, recent use of steroids, or a high refractive error were excluded. Nine subjects were excluded because of recent completion of systemic steroid therapy $(n=3)$, and family history of glaucoma $(n=6)$. Overall, only intraocular pressure readings obtained from 60 eyes of 60 subjects ( 30 men and 30 women) were included in the statistical analysis. The sample size was calculated on average values of intraocular pressure obtained with a Goldmann applanation tonometer to warrant a power of $80 \%$ with a statistical significance level of 0.05 .

\section{Measurement procedure}

All measurements of intraocular pressure were taken between $2 \mathrm{pm}$ and $4 \mathrm{pm}$ to minimize the effect of diurnal variations on intraocular pressure measurements. ${ }^{17-19}$ All measurements were obtained in a sitting position, and for the PT100 slit lamp-mounted and Goldmann applanation tonometer, measurements were taken only after proper alignment of the patient on a slit lamp.

A total of nine intraocular pressure measurements were obtained for each patient in each measurement session. The average of triplicate intraocular pressure measurements for each subject formed the data points used for our statistical analysis. For assessment of repeatability of the different techniques, subjects were required to return for a second measurement session separated by one week.

In session 1, the eye assessed and the order of all intraocular pressure measurements obtained by PT100 were randomized. Goldmann applanation tonometer measurements were performed after use of the noncontact tonometer to eliminate the reported possible effect of ocular massage by the Goldmann applanation tonometer. ${ }^{20}$ In the second measurement session, except for randomization, the order of use of the instruments and the eye assessed was the same as in session 1. Randomization was by a set of random numbers generated from Microsoft Excel (2003; Microsoft, Redmond, WA).

For measurements of intraocular pressure by PT100, all outlying readings (that varied by $4 \mathrm{mmHg}$ compared with other measurements) and those having a low confidence interval (marked with an asterisk or put in brackets) were repeated. ${ }^{11}$ For Goldmann applanation tonometer measurements, one drop of $0.4 \%$ oxybuprocaine hydrochloride was used for each tonometry measurement session. Saline wetted fluorescein was then applied to the superior bulbar conjunctiva before each session measurement was obtained. The tonometer drum was reset to $10 \mathrm{mmHg}$ and recorded by a second clinician (JC) after each reading was obtained. To reduce observer bias, one experienced examiner made all tonometry measurements.

\section{Statistical analysis}

All statistical analysis was performed using GraphPad Instat for Windows program (v 3.10; GraphPad Software Inc, San Diego, CA, www.graphpad.com). Normal distribution of variables was assessed using the Kolmogorov-Smirnov test. The mean \pm standard deviation [SD] of the average intraocular pressure readings is stated in the results along with the minimum and maximum intraocular pressure values in each session and with each technique. Descriptive statistics were used to summarize the data for the sets of measurement using the three techniques. A repeated-measures analysis of variance was performed once to evaluate the differences between instruments and between sessions. The columns analyzed were: Goldmann applanation tonometer vs PT100 handheld vs PT100 slit lamp-mounted (session 1); Goldmann applanation tonometer vs PT100 handheld vs PT100 slit lamp-mounted (session 2). The 95\% limits of agreement (mean of the difference $\pm 1.96 \mathrm{SD}$ of differences) were also depicted in a combined session Bland and Altman ${ }^{19}$ plot of mean difference (between techniques) against the averages for each pair of techniques (ie, Goldmann applanation tonometer vs handheld, Goldmann applanation tonometer vs slit lamp-mounted, and handheld vs slit lamp-mounted).

\section{Assessment of repeatability of the three techniques}

A measurement technique is considered repeatable if repeated measurements obtained in the same individual produce the same results. ${ }^{17}$ This is usually done to ensure that factors contributing to the variability of results remain constant and exert little or no influence on the final result.

Intrasession and intersession repeatability coefficients were calculated using the Bland-Altman ${ }^{21}$ formula of $1.96 \times \mathrm{SD}^{\text {mean differences }}$ for both positions of the PT100 and for the Goldmann applanation tonometer. In each session and for each technique, the intrasession repeatability coefficient was calculated using the mean differences of the triplicate intraocular pressure measurements obtained for each subject. The mean intersession difference was plotted against the averages of sessions 1 and 2 of same technique 
using the Bland-Altman formula, and $95 \%$ confidence limits were depicted. To assess the magnitude of intrasession and intersession differences, repeated-measures analysis of variance was conducted on the columns of averages in each session. The columns considered in this analysis were: Goldmann applanation tonometer session 1 vs session 2; PT100 handheld session 1 vs session 2; and PT100 slit lampmounted session 1 vs session 2 .

\section{Results}

Sixty eyes from 60 subjects divided equally among men $(\mathrm{n}=30,50 \%)$ and women $(\mathrm{n}=30,50 \%)$ aged $22 \pm 1$ (range 20-24) years were used for statistical analysis in this study.

\section{Mean intraocular pressure readings}

Table 1 shows the average ( $\pm \mathrm{SD})$ and range of readings for intraocular pressure obtained with each of the techniques used in this study at each measurement session. On average, the Goldmann applanation tonometer showed the highest mean values for intraocular pressure, followed very closely by the handheld PT100, with the slit lamp-mounted PT100 showing the lowest mean values.

\section{Agreement between intraocular pressure measurements using the three techniques}

In sessions 1 and 2, no significant differences in intraocular pressure measurements were found between the Goldmann applanation tonometer and handheld PT100 $(P>0.05)$, Goldmann applanation tonometer and slit lamp-mounted $(P>0.05)$, and between handheld and slit lamp-mounted PT100 $(P>0.05)$. Figures 1-3 illustrate the agreement between techniques represented as a combined session Bland-Altman plot of the mean difference against the averages of two techniques (Goldmann applanation tonometer vs handheld, Figure 1; Goldmann applanation tonometer vs slit lamp-mounted, Figure 2;

Table I Average, standard deviation, and range (minimum and maximum) of intraocular pressure measurements $(\mathrm{mmHg})$ obtained by Goldmann applanation tonometer, PTI00 handheld, and PTIO0 slit lamp-mounted

\begin{tabular}{lccll}
\hline Parameter & Mean & SD & Minimum & Maximum \\
\hline Session I & & & & \\
GAT & 14.86 & 3.26 & 6.33 & 21.33 \\
Handheld & 14.52 & 3.28 & 7.67 & 23.33 \\
Slit lamp-mounted & 14.01 & 2.80 & 8.33 & 19.67 \\
Session 2 & & & & \\
GAT & 15.16 & 2.42 & 8.67 & 20.67 \\
Handheld & 15.26 & 2.11 & 7.33 & 18.67 \\
Slit lamp-mounted & 15.16 & 2.34 & 8.67 & 20.33 \\
\hline
\end{tabular}

Abbreviations: GAT, Goldmann applanation tonometer: SD, standard deviation.



Figure I A Bland-Altman plot of the mean difference in intraocular pressure measurements between the Goldmann applanation tonometer and PTI00 noncontact tonometer in a handheld position as a function of their averages in both sessions. Solid straight lines are for session I and dotted lines for session 2.

Abbreviations: IOP, intraocular pressure; GAT, Goldmann applanation tonometer; $\mathrm{HH}$, hand-held.

slit lamp-mounted vs handheld, Figure 3) with 95\% limits of agreement shown. Using linear regression, intraocular pressure with the Goldmann applanation tonometer was correlated significantly with the slit lamp-mounted intraocular pressure (Pearson's $r=0.5498,0.5510 ; P<0.0001$ ) and handheld intraocular pressure (Pearson's $r=0.5748,0.5618 ; P<0.0001$ ) measurements in sessions 1 and 2 , respectively.

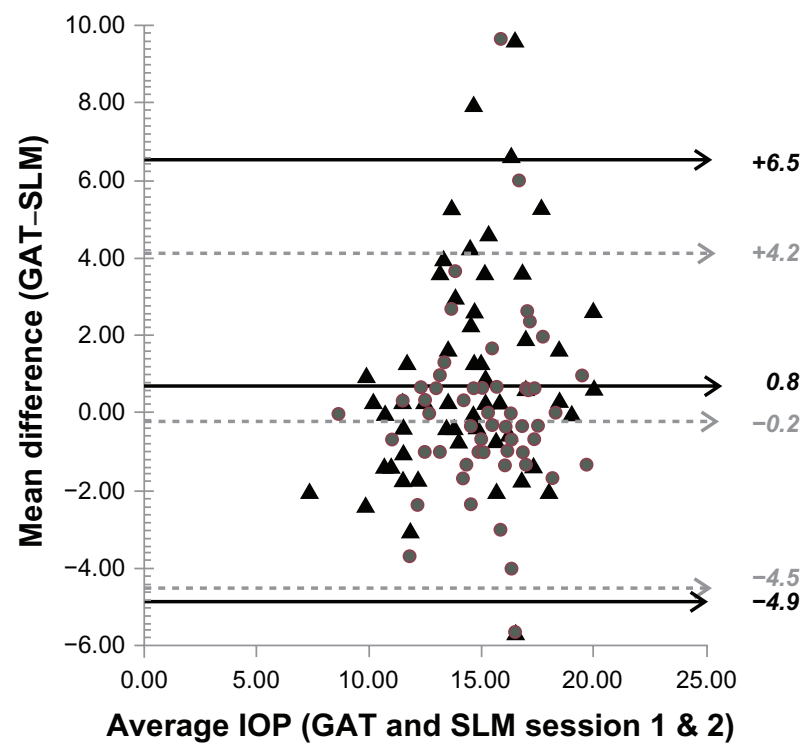

Figure 2 A Bland-Altman plot of the mean difference in intraocular pressure measurements between the Goldmann applanation tonometer and the PTI00 noncontact tonometer in a slit lamp-mounted position as a function of their averages in both sessions. Solid straight lines are for session I and dotted lines for session 2. Abbreviations: IOP, intraocular pressure; GAT, Goldmann applanation tonometer; SLM, slit lamp-mounted. 


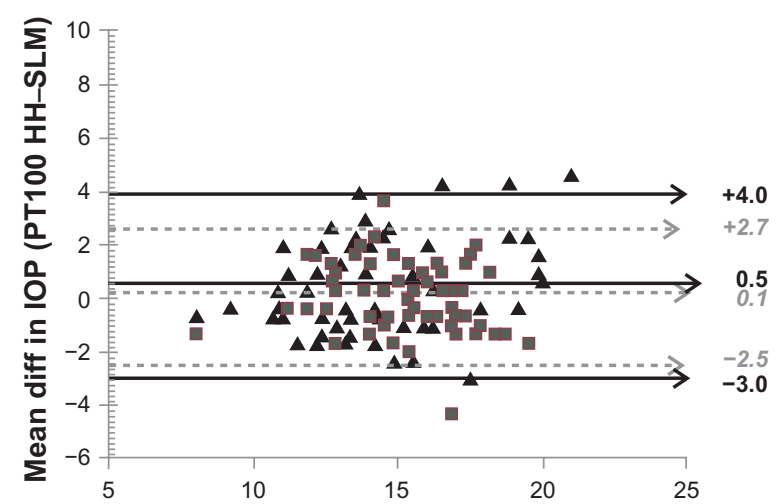

Average IOP PT100 HH and SLM (session $1 \&$ 2)

Figure 3 A Bland-Altman plot of the mean difference in intraocular pressure measurements between the PTI00 noncontact tonometer in a slit lamp-mounted position and in a handheld position as a function of their averages in both sessions. Solid straight lines are for session I and dotted lines for session 2.

Abbreviations: IOP, intraocular pressure; $\mathrm{HH}$, hand-held; SLM, slit lamp-mounted.

\section{Intrasession and intersession repeatability of intraocular pressure measurements}

For the Goldmann applanation tonometer and handheld techniques, repeated-measures analysis of variance showed that mean intrasession and intersession differences in intraocular pressure did not vary in session $1(P>0.05)$ or in session $2(P>0.05)$. For the slit lamp-mounted technique, a small but statistically significant $(P<0.05)$ mean intrasession difference in intraocular pressure of about $1.15 \mathrm{mmHg}$ was observed on analysis.

The intrasession repeatability coefficients for the Goldmann applanation tonometer $( \pm 2.03 / \pm 2.28 \mathrm{mmHg}$ sessions 1 and 2$)$, PT100 handheld $( \pm 2.64 / \pm 2.49 \mathrm{mmHg}$, sessions 1 and 2$)$, and PT100 slit lamp-mounted $( \pm 2.08 / \pm 1.77 \mathrm{mmHg}$, sessions 1 and 2) were comparable in both sessions, but superior for PT100 slit lamp-mounted. The intrasession difference in intraocular pressure for the three techniques was within $\pm 0.5 \mathrm{mmHg}$.

The intersession repeatability coefficient was similar for the Goldmann applanation tonometer $( \pm 4.75 \mathrm{mmHg})$ and slit lamp-mounted $( \pm 4.80 \mathrm{mmHg})$, which was better in comparison with handheld $( \pm 5.68 \mathrm{mmHg})$.

Intersession repeatabilities are represented as a BlandAltman plot of mean difference against averages of the Goldmann applanation tonometer (Figure 4), handheld (Figure 5), and slit lamp-mounted (Figure 6) with the 95\% limits of repeatability depicted. The intersession difference in intraocular pressure for each technique was within $\pm 1 \mathrm{mmHg}$ for all techniques.

\section{Discussion}

In this study we assessed the precision of intraocular pressure measurement using the PT100 noncontact tonometer in two

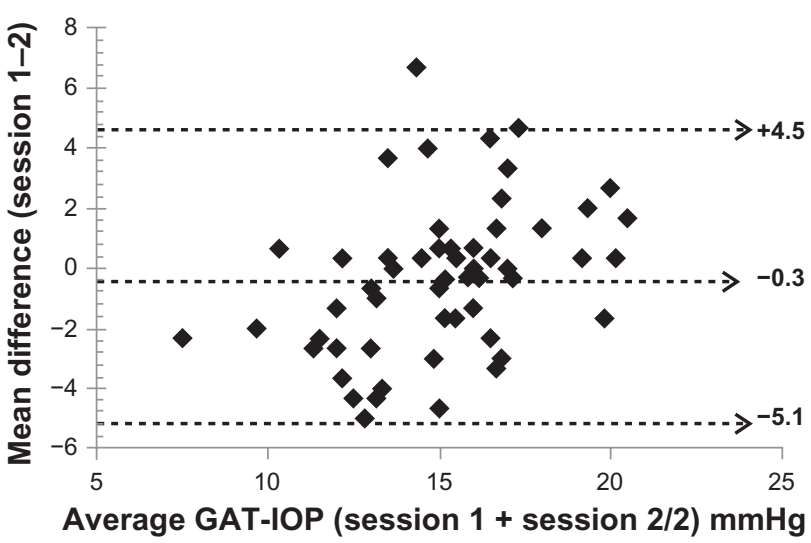

Figure $4 \mathrm{~A}$ Bland-Altman plot of the mean intersession difference of the Goldmann applanation tonometer intraocular pressure as a function of the averages in sessions $\mathrm{I}$ and 2.

Abbreviations: GAT, Goldmann applanation tonometer; IOP, intraocular pressure.

different positions, ie, handheld and slit lamp-mounted, as compared with Goldmann applanation tonometer values. A previous study ${ }^{11}$ had suggested that improper fixation might be a major limitation to intraocular pressure measurements obtained with the PT100.

The intrasession intraocular pressure variations for the Goldmann applanation tonometer, handheld and slit lampmounted, did not differ significantly in sessions 1 and 2 for the same technique, and furthermore, the mean intersession intraocular pressure differences for the three techniques did not vary. Although the slit lamp-mounted intraocular pressure measurements varied significantly between sessions by $1.15 \mathrm{mmHg}$, the difference was not clinically important because intraocular pressure obtained by noncontact tonometer can vary between consecutive measurements by as much as $7 \mathrm{mmHg}$. This suggests that the three techniques used in this study have a similar consistency in measurements of intraocular pressure within a session.

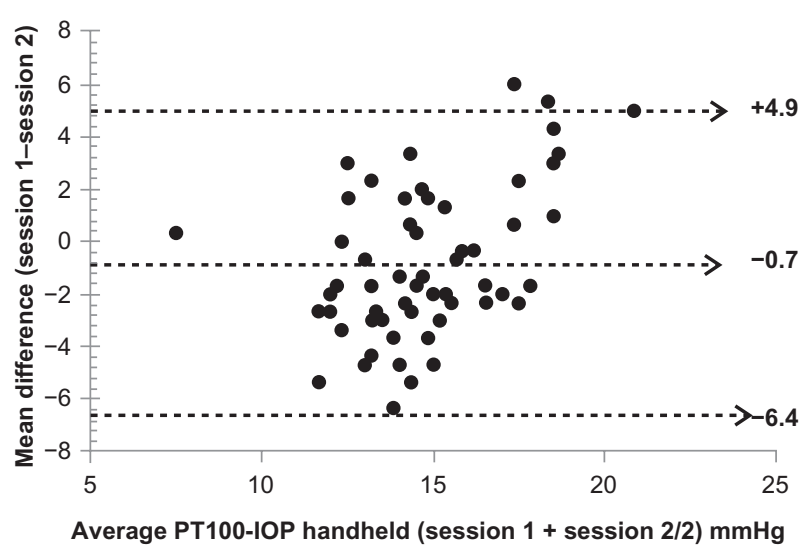

Figure 5 A Bland-Altman plot of the mean intersession difference of the PTI00 in a handheld position as a function of the averages in sessions $I$ and 2 .

Abbreviation: IOP, intraocular pressure. 


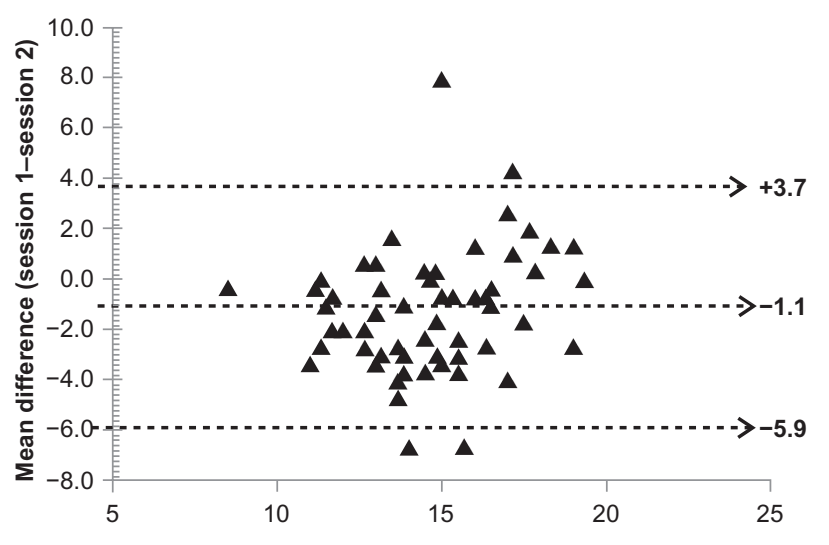

Average PT100-IOP slit lamp-mounted (session $1+2 / 2$ ) $\mathrm{mmHg}$

Figure 6 A Bland-Altman plot of the mean intersession difference of the PTI00 in a slit lamp-mounted position as a function of the averages in sessions I and 2 . Abbreviation: IOP, intraocular pressure.

In agreement with the suggestion of Salim et al, ${ }^{11}$ the stability introduced to the PT100 intraocular pressure measurements (by mounting it on a slit lamp) improved its precision because the intrasession $( \pm 2.08 \mathrm{mmHg}, \pm 1.77 \mathrm{mmHg}$, session 1 and 2) and intersession repeatability coefficients $( \pm 4.80 \mathrm{mmHg}$ ) were superior to those of the handheld PT100 (intrasession $\pm 2.64 \mathrm{mmHg}, \pm 2.49 \mathrm{mmHg}$, session 1 and 2 ; intersession $\pm 5.68 \mathrm{mmHg}$ ) and slightly better than that of Goldmann applanation tonometer (intrasession $\pm 2.03 \mathrm{mmHg}, \pm 2.28 \mathrm{mmHg}$, session 1 and 2; intersession $\pm 4.75 \mathrm{mmHg}$ ). However, all three techniques produced reliable intraocular pressure measurements within and between sessions. These findings were comparable with the repeatability coefficients $(1.8 \mathrm{mmHg}$ and $2.1 \mathrm{mmHg}$, Goldmann applanation tonometer sessions 1 and 2; 1.9 and $1.8 \mathrm{mmHg}$ PT100 handheld sessions 1 and 2) reported in another study $;{ }^{15}$ this study also reported the repeatability coefficient for test-retest differences of both techniques to be within $\pm 5 \mathrm{mmHg}$, which is similar to that found in the current study ( $\pm 6 \mathrm{mmHg}$ ).

The difference in intraocular pressure measurements between techniques did not differ significantly $(P>0.05)$ in both sessions, thus PT100 in both positions and Goldmann applanation tonometer can be used interchangeably for the measurement of intraocular pressure in normal subjects. This reaffirms the findings of Almubrad..$^{15}$ Overall, Goldmann applanation tonometer and PT100 handheld intraocular pressure measurements were consistently higher than PT100 slit lampmounted intraocular pressure values, whereas a comparison of Goldmann applanation tonometer and handheld intraocular pressure values resulted in Goldmann applanation tonometer measurements being insignificantly higher in session 2 while handheld was insignificantly higher in session 1.
The mean intraocular pressure in the present observation (14.89 mmHg, $14.58 \mathrm{mmHg}, 15.01 \mathrm{mmHg}$, for handheld, slit lamp-mounted, and Goldmann applanation tonometer, respectively) is comparable with that reported in two previous studies (15.98 mmHg, $15.65 \mathrm{mmHg}$, PT100 and Goldmann applanation tonometer, respectively), ${ }^{11}$ and $15 \mathrm{mmHg}$ for both PT100 and Goldmann applanation tonometer. ${ }^{15}$ However, in one of the studies, ${ }^{11}$ the variability in intraocular pressure measurements using both techniques $( \pm 5.98 \mathrm{mmHg}$ and $\pm 4.26 \mathrm{mmHg}$ for the PT100 and Goldmann applanation tonometer, respectively) was larger than that obtained in the present study $( \pm 2.35 \mathrm{mmHg}, \pm 2.27 \mathrm{mmHg}$, and $\pm 2.61 \mathrm{mmHg}$, for handheld, slit lamp-mounted, and Goldmann applanation tonometer, respectively). This is probably a reflection of the older subjects enrolled in the study by Salim et al.

It was the aim of this study to compare the PT100 noncontact tonometer with the Goldmann applanation tonometer which is the clinical gold standard for intraocular pressure measurements. Many intraocular pressure studies have shown good clinical agreement between the noncontact tonometer and Goldmann applanation tonometer, with lower consistency in noncontact tonometry when the pressure is in the higher range. ${ }^{2,5,7,13,22}$ In our study, within the normal range of intraocular pressure levels, PT100 in both positions demonstrated a close level of agreement when compared with the Goldmann applanation tonometer, as depicted by the Bland-Altman plots of agreement.

To the best of our knowledge, this is the first study to demonstrate the variation in intraocular pressure measurements obtained when PT100 is used in the handheld and slit lamp-mounted position. The study is limited by the lack of patients with increased intraocular pressure, and the narrow age group of subjects recruited, because the noncontact tonometer has been shown to be less accurate with higher pressures. ${ }^{2,5,7,13,22}$ There is also a possibility that central corneal thickness and curvature of the cornea may have influenced the intraocular pressure results obtained in this study. Studies have continuously shown that, while corneal curvature radius, ${ }^{23}$ the elastic properties of the cornea, ie, rigidity and stiffness, ${ }^{14,23-26}$ can influence intraocular pressure accuracy obtained by the Goldmann applanation tonometer and the noncontact tonometer, the noncontact tonometer is more affected by central corneal thickness than the Goldmann applanation tonometer. ${ }^{12,14,26}$ Therefore, the data in the current study are limited by the lack of central corneal thickness and cornea curvature measurements for adequate comparison. Studies comparing the two position measurements of intraocular pressure obtained by the PT100 with 
the Goldmann applanation tonometer in subjects with higher intraocular pressure ranges should consider recruiting subjects of various age groups, and determining central corneal thickness measurements in those subjects. This is to verify if similar findings occur for higher intraocular pressure ranges, and determine the effects of the cornea biomechanical properties on intraocular pressure obtained with the PT100.

Nevertheless, this study suggests that the lack of head and chin rests may have an influence on the precision of PT100 intraocular pressure measurements obtained in a handheld position with respect to the Goldmann applanation tonometer, but does not result in any significant variation in intraocular pressure measurements obtained on repositioning the instrument.

Generally, a repositioning of the PT100 from the conventional hand-held position to a slit lamp-mounted position not only improved its precision but also reduced the variation in intraocular pressure measurements reported ${ }^{11,14}$ when the Goldmann applanation tonometer was compared with the PT100. There was no difference in the variation between the two positions of the PT100 with respect to the Goldmann applanation tonometer in session 1 (11.39 mmHg/11.82 mmHg, slit lamp-mounted/handheld) and in session $2(8.56 \mathrm{mmHg} / 8.25 \mathrm{mmHg}$, slit lamp-mounted/ handheld). Therefore, in a clinic setting, and for research purposes, incorporation of a head-rest or stabilizing the PT100 on a slit lamp will enhance the precision of the instrument. However, outside a clinic setting where intraocular pressure measurements might be obtained by medical personnel or nonmedical personnel, handheld positioning of the PT100 is still the preferred technique because its portability is beneficial.

The PT100, like other portable tonometers, makes noncontact glaucoma screening a possibility, given that the use of tonometry in glaucoma screening has been an ongoing debate, and appearing to be of limited diagnostic value as a solitary test. ${ }^{29}$ However, it is commonly performed in glaucoma screenings in and out of clinic in conjunction with other diagnostic modalities. ${ }^{30,31}$ Screenings may be done by nonmedical and unlicensed personnel. Because noncontact tonometry does not require topical anesthetic or staining drops and the readings are infrequently affected by the operator, it allows screenings to be implemented without the direct supervision of medical doctors, allowing screening staff relative independence in operation. ${ }^{22}$

In conclusion, the three techniques are consistent in their measurement of intraocular pressure in the same session and between sessions. The difference in intraocular pressure measurements between techniques did not differ significantly
$(P>0.05)$ in both sessions, and therefore the three techniques can be used interchangeably for measurement of intraocular pressure in normal young adults.

\section{Disclosure}

The authors report no conflicts of interest in this work.

\section{References}

1. VanVeldhuisen PC, Ederer F, Douglas GA, et al. The Advanced Glaucoma Intervention Study (AGIS): 7. The relationship between control of intraocular pressure and visual field deterioration. $\mathrm{Am} \mathrm{J}$ Ophthalmol. 2000;130:429-440.

2. Ogbuehi KC. Assessment of the accuracy and reliability of the Topcon CT80 non-contact tonometer. Clin Exp Optom. 2006;89:310-314.

3. Fernandez P, Diaz-Rey JA, Queiros A, Gonzalez-Meijome JM, Jorge J. Comparison of the ICare rebound tonometer with the Goldmann tonometer in a normal population. Ophthalmic Physiol Opt. 2005;25: 436-440.

4. Cuckburn DM. Tonometry. In: Eskridge JB, Amos J, Barlett JD, editors. Clinical Procedures In Optometry. 1st ed. Philadelphia, PA: Lippincott, Willams and Wilkins; 1991.

5. Lam AK, Chan R, Chiu R, Lam C. The validity of a new noncontact tonometer and its comparison with the Goldmann tonometer. Optom Vis Sci. 2004;81:601-605.

6. Goldmann H, Schmidt T. Applanation tonometry. Ophthalmologica. 1957;134:221-242. German.

7. Regine F, Scuderi GL, Cesareo M, Ricci F, Cedrone C, Nucci C. Validity and limitations of the Nidek-4000 non-contact tonometer: A clinical study. Ophthalmic Physiol Opt. 2006;26:33-39.

8. Al Mubrad TM, Ogbuehi KC. The effects of repeated applanation on subsequent IOP measurements. Clin Exp Optom. 2008;91: 524-529.

9. Forbes M, Pico G Jr, Grolman B. A noncontact applanation tonometer. Description and clinical evaluation. Arch Ophthalmol. 1974;91: 134-140.

10. Garcia-Resua C, Fernandez GMJ, Yebra-Pimentel E, Garcia-Montero S. Clinical evaluation of the Canon TX-10 noncontact tonometer in healthy eyes. Eur J Ophthalmol. 2010;20:523-530.

11. Salim S, Linn DJ, Echols II JR, Netland PA. Comparison of intraocular pressure measurements with the portable PT100 noncontact tonometer and Goldmann applanation tonometry. Clin Ophthalmol. 2009;3: 341-344.

12. Tonnu PA, Ho T, Sharma K, White E, Bunce C, Garway-Heath D. A comparison of four methods of tonometry: Method agreement and interobserver variability. Br J Ophthalmol. 2005;89:847-850.

13. Jorge J, Gonzalez-Meijome JM, Diaz-Rey JA, Almeida PR, Parafita MA. Clinical Performance of non-contact tonometry by Reichert AT550 in glaucomatous patients. Ophthalmic Physiol Opt. 2003;23:503-506

14. Murase H, Sawada A, Mochizuki K, et al. Effects of corneal thickness on intraocular pressure measured with three different tonometers. Jpn J Ophthalmol. 2009;53:1-6.

15. Almubrad TM. Performance of the PT100 noncontact tonometer in healthy eyes. Clin Ophthalmol. 2011;5:661-666.

16. McCaghrey GE, Matthews FE. The Pulsair 3000 tonometer - how many readings need to be taken to ensure accuracy of the average? Ophthalmic Physiol Opt. 2001;21:334-338.

17. Noel C, Kabo AM, Romanet JP, Montmayeur A, Buguet A. Twentyfour-hour time course of intraocular pressure in healthy and glaucomatous Africans: Relation to sleep patterns. Ophthalmology. 2001;108: 139-144.

18. Liu JH, Kripke DF, Twa MD, et al. Twenty-four-hour pattern of intraocular pressure in the ageing population. Invest Ophthalmol Vis Sci. 1999;40:2912-2917. 
19. Bland JM, Altman DG. Statistical methods for assessing agreement between two methods of clinical measurement. Lancet. 1986;1:307-310.

20. Krakau CE, Wilke K. On repeated tonometry. Acta Ophthalmol (Copenh). 1971;49:611-614.

21. Bland JM, Altman DG. Applying the right statistics: Analysis of measurement studies. Ultrasound Obstet Gynecol. 2003;22:85-93.

22. Moreno-Montanes J, Gomez-Demmel E, Lajara-Blesa J, Aliseda-Perez D. Comparative study of three non-contact tonometers and the Goldmann tonometer. Ophthalmologica. 1994;208:115-118.

23. Whitacre MM, Stein R. Sources of error with use of Goldmann-type tonometers. Surv Ophthalmol. 1993;38:1-30.

25. Medeiros FA, Weinreb RN, Hassanein K. The effects of corneal biomechanical properties on intraocular pressure measurements using the ocular response analyzer. J Glaucoma. 2006;15:364-370.

26. Harada Y, Hirose N, Kubota T, Tawara A. The influence of central corneal thickness and corneal curvature radius on the intraocular pressure as measured by different tonometers: Noncontact and Goldmann applanation tonometers. J Glaucoma. 2008;17:619-625.
27. Tonnu P-A, Ho T, Newson T, et al. The influence of central corneal thickness and age on intraocular pressure measured by pneumotonometry, non-contact tonometry, the Tono-Pen XL, and Goldmann applanation tonometry. Br J Ophthalmol. 2005;89:851-854.

28. Ko Y-C, Liu C-J, Hsu W-M. Varying effects of corneal thickness on intraocular pressure measurements with different tonometers. Eye. 2005; 19:327-332.

29. Sponsel WE. Tonometry in question: Can visual screening tests play a more decisive role in glaucoma diagnosis and management? Surv Ophthalmol. 1989;33:291-300.

30. Mundorf TK, Zimmerman TJ, Nardin GF, Kendall KS. Automated perimetry, tonometry, and questionnaire in glaucoma screening. Am J Ophthalmol. 1989;108:505-508.

31. Tuck MW, Crick RP. The cost-effectiveness of various modes of screening for primary open angle glaucoma. Ophthalmic Epidemiol. 1997;4:3-17.
Clinical Ophthalmology

\section{Publish your work in this journal}

Clinical Ophthalmology is an international, peer-reviewed journal covering all subspecialties within ophthalmology. Key topics include: Optometry; Visual science; Pharmacology and drug therapy in eye diseases; Basic Sciences; Primary and Secondary eye care; Patient Safety and Quality of Care Improvements. This journal is indexed on

\section{Dovepress}

PubMed Central and CAS, and is the official journal of The Society of Clinical Ophthalmology (SCO). The manuscript management system is completely online and includes a very quick and fair peer-review system, which is all easy to use. Visit http://www.dovepress.com/ testimonials.php to read real quotes from published authors. 